\title{
Factors Affecting Health Instruction in Secondary Schools in Edo State, Nigeria
}

\author{
C.O. Idehen and O.G. Oshodin*
}

\author{
Department of Health, Environmental, Education and Human Kinetics, Faculty of Education, \\ University of Benin, Benin City, Nigeria \\ E-mail: ideheneducation@yahoo.co \\ *Faculty of Education, University of Benin, Benin City, Nigeria
}

KEYWORDS School authorities; healthful school living; health education curriculum implementation; instructional materials; health science

\begin{abstract}
The primary objective of this paper was to determine the factors that affects health instruction in secondary schools in Edo State, Nigeria. The descriptive survey research method was used for the study and data were analyzed descriptively using frequency count and percentages. The results of the study reveals that school principals negative administrative styles and the inadequacy of duration/time allotted to health instruction in the schools were critical factors that affects health instruction in Edo State secondary schools. The study equally show that lack of health education teachers, lack of relevant health education textbooks, pamphlets and posters were factors central to the poor state of health instruction in Edo State secondary schools. Based on the findings, the authors made several recommendations including the need for school authorities in Edo State to provide relevant and modern textbooks, pamphlets, posters, computers and other related instructional materials. It was also recommended that the State's Ministry of Education should help in enhancing the tenets of health education by posting at least one experienced health education staff in the Inspectorate Division of the Ministry had been assigned the responsibility of visiting the schools regularly in order to ensure that the schools, students and teachers are adequately implementing the health education curriculum.
\end{abstract}

\section{INTRODUCTION}

Studies by Eke (1989) and Idehen (2004) reveal that in many parts of Nigeria, health instruction in secondary schools was poorly carried out. The non implementation of the instructional components of the health education curriculum, lack of infrastructure and instructional materials where mainly the problems identified by the researchers as responsible for the poor status of health education in Nigerian school system. It is significant to mention that in whatever function one finds oneself, the most important factor is good health. If health is lacking, productivity will be seriously undermined. Thus every health education teacher in Nigeria has the potential for positively affecting the health status of students. Furthermore, many students contend with health problems that influence their ability to learn. For instance, some students are not adequately fed, others lack relevant vaccination and are vulnerable to various infections and diseases such as tuberculosis, measles, meningitis, malaria and infective hepatitis. Studies by Iverson(2000) reveal that many students are brought up in families in which domestic violence and drug or chemical dependency are the rule rather than the exception. These observations compel and make necessary the provision and adequate implementation of health education curriculum in schools.

Health education instructional objectives are expected to provide health knowledge, enhance wellness behaviors, promote health situations, facilitate healthful relationships and enable students make responsible decisions. An earlier report (Bernard,1992) on the objectives of health instruction include that it can help learners to develop resistance skills when appropriate, promote protective factors, ensure resilience in terms of the ability to prevent or to recover from sickness and to promote health literacy.

Studies by Dawson (1997), Frank ham (1998) and Gold (1999) reveal the significance of health instruction and they concluded that health instruction is effective in reducing many highrisk behaviors, teenage pregnancies, smoking rates among young people. But its over all effectiveness depends on many factors such as the quality of the teachers providing health instruction, the available instructional materials in terms of textbooks, pamphlets, posters and other available infrastructural facilities such as play fields, toilets, comprehensiveness of the health education programme, time available for instruc- 
tion, family involvement and community participation in matters related to health education.

Health education, in its various nomenclatures has been a part of the school curriculum in Nigeria since the early twenties. Health education curriculum development in Nigeria actually started with hygiene and sanitation as school subjects. An earlier report by Ejifugha (1999) reveal that serious efforts were made by the British Social Hygiene Council to teach hygiene in Nigerian schools. Initially, the efforts towards the resolution of the confusion as to what should be taught in hygiene class led to a series of conferences and memoranda. The introduction of the new terminology, health education, which shifted emphasis to the principles of healthful living was based on the fact that the contents of hygiene were inadequate for the promotion of healthful living. In 1984, the term health education was introduced as one of the school subjects in Nigeria. The health education curriculum has become a reality today in Nigeria because of government's concern for the health status of school children. The present national health education curriculum was developed by the Federal Ministry of Education between 1980 and 1984 and finally approved for implementation in the nation's secondary schools in August 1985 (Federal Ministry of Education, 1985)

Studies by Owie (1992) had earlier revealed that the implementation of the approved health education curriculum in Nigerian secondary schools was done under the nomenclature of health science. This approach was adopted because it was alleged that the term "education" in health curriculum should not be for the secondary school level, hence health science. The present health education curriculum has ten instructional units, which are to be implemented by secondary schools in Nigeria. The ten units include:

Unit 1: Growth and development

Unit 2: Food and nutrition

Unit 3: Physical health

Unit 4: Safety and accident prevention

Unit 5: Prevention and control of communicable diseases

Unit 6: Community and environmental health

Unit 7: Family life and sex education

Unit 8: Emotional and social health

Unit 9: Chemicals which alter behavior

Unit10:Consumer health, (Federal Ministry of Education, 1985)

These ten units of the health education curriculum are theoretically and practically planned to address the physical, mental, emotional and social dimensions of the health of school children. If the ten units are adequately implemented, they could motivate and assist students to maintain and improve their health, prevent disease and reduce health related risk behavior. Ideally, secondary schools in Nigeria are expected to implement the curriculum to the fullest and Udoh (1996) had earlier reported that it seems that Nigerian secondary schools have not lived up to the expectation in terms of implementing some aspects of the health education curriculum. The inability of Nigerian secondary schools to implement the health education curriculum may have been due to certain constraints. A preliminary analysis of the status of health education in Nigerian secondary schools provided some baseline information on the range of constraints that might have affected the implementation of the curriculum. Prominent among the constraints include lack of health education textbooks, poor quality of instruction, poor execution of curriculum contents, inadequate funding, insufficient standard facilities and lack of coordinated programme implementation.

In spite of the several researches that have being carried out to examine the issues and problems pertaining to health instruction in Nigerian schools, non have attempted to address the role of school administrators. Although Shuck smith and Wood (1998) had earlier reported that administrative factors have little or no influence over health instruction in schools. This study is intended to bridge the gap in knowledge about what factors impinges on health instruction in Nigerian schools and to evaluate the factors that influences the teaching of health education in Nigerian secondary schools.

The following research questions were developed to enable a critical study of the factors affecting health instruction in Nigerian secondary schools.

a. Do administrative related problems affect health instruction in Nigeria secondary schools?

b. Do teacher related problems affect health instruction in Nigeria secondary schools?

c. What do students consider as problems affecting health instruction in their schools?

\section{THE DESIGN OF THE STUDY}

The descriptive survey research method was 
used for the study. An earlier report (Bowling,1999) reveal that survey research enables the collection of detailed and factual information. Survey research also describes existing phenomenal and it also justifies current conditions and practices.

\section{The Population of the Study}

The population of this study consisted of all public secondary schools in Edo State where health education is being offered and all the teachers and students in such schools.

\section{Sample and Sampling Procedure}

There were no official records in either the Edo State Ministry of Education or the Post Primary Education Board of the number of schools offering health education in the state. However, a preliminary survey of all the secondary schools in the state carried out by the researchers showed that 18 secondary schools out of 332 secondary schools were offering health education at the time of the study.

These 18 schools thus constituted the institutional population of the study. The schools were clustered and the population was stratified into senatorial districts. The schools were then randomly selected to provide proportional random representation. Thirteen senior secondary schools were finally selected as the study sample. These institutions, their teachers and students were used for the study because they constituted the most readily accessible source of information about the execution of health education curriculum in the state.

The choice of stratified/proportional random sampling was to ensure proper representation of each of the homogenous subgroups in the sample. Thirteen health education teachers and one hundred and eighty students were used as respondents.

\section{Description of Research Instruments}

The instruments for this study were two sets of questionnaire designed by the researchers and checklist. Studies by Bowling (1999) reveal that the use of questionnaire for survey research was the best instrument for collecting data because as surveys are carried out in natural settings, questionnaire increases the external validity of the study.
There were two sets of questionnaire for this study .The Teachers Questionnaire and Students Questionnaire. The question were developed based on information and experiences derived from review of literature on health education curriculum implementation strategies as contained in earlier reports (Harrelson, Oberteuffer and Pollock, 1985).

Validity of Instruments: In order to ensure the validity of the instruments, the self-structured sets of questionnaire were referred to four experts in the fields of curriculum, health education and psychology for vetting so as to ensure its appropriateness, relevance and clarity. This helped in the content validity process of the instruments.

Reliability of Instruments: After the revision and validation of the research instruments. Testretest measure of reliability was applied to the two sets of questionnaire (i.e. The Teachers and Students Questionnaire) and reliability coefficient of 0.87 and 0.83 were obtained respectively. These were considered high enough to ensure reliability of the instruments.

Administration of the Instruments: Copies of the questionnaire were personally administered to the respondents. The respondents were briefed on the purpose of the research and the questionnaire with the intention of disabusing their minds from the notion that they were been probed.

Data Analysis: The completed sets of questionnaire were collected and analyzed using descriptive statistics of frequency counts and percentages. Studies by Bowling (1999) reveal that descriptive statistics were considered adequate in research situations where there are only two categories for classifying observations such as the yes or no types.

\section{RESULTS}

Table 1 presents the teachers responses in relation to administrative issues that impinge on health instruction in schools.

Results in table 1 reveals that $69.23 \%$ of the respondents indicated that the school administration made provision for health instruction, a welcome development for the health education curriculum. On the issue of whether the school principals leadership style affected health instruction, $53.85 \%$ of the respondents indicatesd "yes" while $46.15 \%$ of the respondents did not agree with this position. However, almost $70 \%$ of the respondents indicated that their school principals 
Table 1: Administrative related problems $\mathbf{N}=13$

\begin{tabular}{|c|c|c|c|c|}
\hline Administrative Related issues & Yes & $\%$ & No & $\%$ \\
\hline Does the school administration make supervision of health instruction? & 9 & 69.23 & 4 & 30.77 \\
\hline Does the school principal leadership style affect health instruction? & 7 & 53.85 & 6 & 46.15 \\
\hline Is the school principal autocratic? & 9 & 69.23 & 4 & 30.77 \\
\hline Or democratic in his style of administration? & 6 & 46.15 & 7 & 53.85 \\
\hline Has a nonchalant attitude? & 9 & 69.23 & 4 & 30.77 \\
\hline Is the atmosphere in which the teacher operate relax and friendly? & 8 & 61.54 & 5 & 38.46 \\
\hline
\end{tabular}

were autocratic. Then $46 \%$ of the respondents indicated that their principals were democratic in their styles of administration. But about $70 \%$ of the respondents indicated that their school principals were nonchalant. It follows that school principals that are autocratic will impose health courses to be taught, the teacher to teach, what content should be implemented, how it should be taught and when it should be taught. Principals who are nonchalant may be indifferent to the sensitivity of health instruction and with these type of school principals, anything goes.

Table 2 presents teachers responses in relation to issues affecting health instruction in Nigerian secondary schools.

In order to further determine the problems militating against health education curriculum implementation in schools, responses of the teachers were sought to the questions in table two. Information in the table shows that more than $61 \%$ of the respondents agreed that the teaching load assigned to them was ideal, while about $39 \%$ of the respondents did not agree with this position. This was followed by $46 \%$ of the respondents that agreed that the period for teaching health per week was ideal. However, almost $54 \%$ of the respondents did not consider the period of teaching health per week as adequate. On the issue of duration or time allocated health instruction in schools, almost 70\% considered the duration or time adequate, while $30 \%$ did not consider the duration or time for health instruction in schools adequate enough. It is evident that health education teachers were experiencing difficulties in implementing the instructional component of the health education curriculum due to problems associated with teaching load and inadequacy of time for adequate health instruction.

Table 3 presents students responses with regard to problems militating against health instruction in their school.

Results in table 3 show that more than $57 \%$ of the respondents indicated that lack of health education teachers was a hindrance to health instruction. This was followed by $86.66 \%$ of the respondents who were of the position that lack of health education textbooks constituted hindrance to health instruction in the schools. Furthermore, about $64 \%$ of the respondents indicated that lack of health education pamphlets was also a problem affecting health instruction in the schools.

Concerning health posters in the schools over $51 \%$ of the respondents perceived lack of posters as a militating factor against adequate implemen-

Table 2: Teacher related problems $\mathbf{N}=\mathbf{1 3}$

\begin{tabular}{lrrrr}
\hline Teachers Related Problems & Yes & $\%$ & No & $\%$ \\
\hline Teaching load assigned to the teacher is ideal & 8 & 61.54 & 5 & 38.46 \\
$\begin{array}{l}\text { The Period for teaching health per week is ideal } \\
\text { The duration/time allotted to health instruction is } \\
\text { meaningful to the realization of instructional objective. }\end{array}$ & 6 & 46.15 & 7 & 53.85 \\
\hline
\end{tabular}

Table 3: Students related problems $\mathbf{N}=\mathbf{1 8 0}$

\begin{tabular}{|c|c|c|c|c|}
\hline & Yes & $\%$ & $\mathrm{No}$ & $\%$ \\
\hline Lack of health education teachers & 103 & 57.23 & 77 & 42.77 \\
\hline Lack of health education textbooks & 156 & 86.66 & 24 & 13.34 \\
\hline Lack of Pamphlets & 115 & 63.89 & 65 & 36.11 \\
\hline Lack of posters & 92 & 51.11 & 88 & 48.89 \\
\hline Lack of interest in health science & 127 & 70.56 & 53 & 29.44 \\
\hline Does the health science teacher stimulate your interest in the subject? & 103 & 57.22 & 77 & 42.78 \\
\hline
\end{tabular}


tation of the instructional related component of health education curriculum in schools.

Similarly, about $71 \%$ of the respondents surveyed considered their personal lack of interest in health education as an impediment to health education curriculum implementation hence poor health instruction.

\section{DISCUSSION}

The evidence from this study points to the fact that health instruction in Nigerian schools system is problematic. At a critical time when emphasis is on prevention of diseases, it is expected that health instruction in the schools will be adequately supported by school authorities, teachers, students, governments and the community. A well-structured pattern of health instruction in schools is an impetus to effective living, health promotion and disease prevention. The problems associated with the absence of health instruction in schools poses a threat and without their timely resolutions, schools would be unable to provide students with the greatest possible assess to variety of learning let alone equip them intellectually, socially and emotionally. Table 1 reveals that schools administration were biased about health instruction. In spite of the seemingly interest of school authorities in health education, they do not provide an ideal teaching and learning environments, moreover, the schools do not have a developed teaching guide outlining progressive plan for health instruction. The aforementioned features shows that health education in schools contends with administrative related problems in schools. This finding is in support of Ejifugha (1999) view that health education in Nigerian schools lack definition due to administrative constraints. This finding also contradicts Shuck smith and Wood (1999) claim that administrative factors have little or no influence over health instruction. There is evidence from extant literature that health education curriculum is most apt to function if school administrators provide the necessary materials for teaching. For schools to do otherwise is to help to incorrectly implement the health education curriculum. However, the findings from this study on health education implementation constraints in Nigerian secondary schools corroborate that of Udoh's (1996) initial finding of low level of implementation by school authorities. Health education is viewed by many school authorities in Nigeria as a weaker form of Biology and Biology is considered as one of the super science subjects.

Another disturbing finding arising from this study, is the period of teaching health per week. In table two, over 53\%(being the highest figure recorded) of the teachers agreed that they found the period for teaching health per week to be inadequate. The absence of an ideal teaching period for health instruction in the schools will certainly compound the process of health education curriculum implementation. The Nigerian Association of Health Education Teachers (NAHET) has suggested a minimum period of time for health instruction in schools to be everyday and that the reality of this depend on the willingness of school authorities, teachers, students and the community to participate in health instructional activities. The Association posited that health is an everyday affair so that repetitive study will enhance health promotion in all circumstances.

The evidence from this study pointed to the fact that school policy, inadequate instructional materials, poor allocation of time to teaching health and lack of qualified teachers militated against health education curriculum implementation in Nigerian secondary school system. Thus if health education must have its rightful place in Nigerian schools, the following must be taken into consideration:

1. The school and government should provide the necessary health education facilities

2. More time should be allocated to teaching health in the schools

3. More qualified health education teachers should be posted to the schools

4. School administrators should be sensitized to the importance of health education ,bearing in mind that there is an approved health education curriculum on ground since 1985.

\section{CONCLUSION}

The inability of school administrations to make provision for health instruction, the periods for teaching health, lack of health education teachers, health education text books, health pamphlets and posters were the stronger factors responsible for poor health instruction. It is plausible to conclude that health instruction in Nigeria secondary system is bedeviled by a number of problems. Thus there is an urgent need to address 
these problems. In seeking to achieve the objectives of health education curriculum vigorous efforts need to be made to improve its teaching in schools as was the case in the 1950s. At that time, health education was reported to have received more attention in Nigerian schools. Ademuwagun (1977) had earlier reported that the 50s in Nigerian history coincided with the colonial rule and health education was taught as hygiene .Regular morning inspections and the hygiene classes conducted were some of the hallmarks of serious health education instructional activities in Nigerian school system. However, the implementation of the health education curriculum has the following implications:

- Inclusiveness, implying that the teachers and students will show interest and benefit from the programme

- Special attention to the duration/time for health instruction

- Encourage the provision of facilities bearing in mind the unique nature of health education. In this case, facilities include classrooms, libraries, playfields, water and sanitation.

\section{RECOMMENDATIONS}

The following recommendations are made with a view to effective health instruction in schools:

1. Health instruction in schools cannot be adequately carried out without instructional resources. Government and school authorities must therefore help to provide instructional materials. Relevant and modern textbooks, pamphlets, posters, computers and other related materials should be provided for students by parents and schools management

2. School authorities should consider health instruction important in the school system. health instruction should be balanced with other instructional subjects in the school for the sakes of fairness, equity and justice which are entranced in democracy.

3. The relevance of health instruction in the Nigerian secondary school system ought to be reconsidered. The philosophy underlining health instruction in schools deserves to be rethought, brought up to date and restated. From this study, it is apparent that many school principals, teachers and students have great misconceptions about the relevance of health instruction.

4. The state Ministry of Education should have at least one experienced health education staff who is familiar with the philosophy, implementation and instructional strategies of health education curriculum. Such staff in the Inspectorate Division of the Ministry should visit the schools regularly to ensure that the teachers are adequately implementing the health education curriculum

\section{REFERENCES}

Ademuwagun, Z.A. 1977. Education Laws Related to Health in Nigeria. Ibadan: Department of Preventive and Social Medicine, University of Ibadan.

Bernard, B. 1992. "How Schools convey high expectations for kids." Western Centre News, 5(3): 11-15.

Bowling, A. 1999. Research Methods in Health: Investigating Health Services. Buckingham: University Press.

Ejifugha, A.U. 1999. Development of Health Education in Nigeria. Owerri: Canon Publisher Nigeria Ltd.

Eke, A.N. 1989. "Status of health education in Anambra secondary schools", (pp. 262-297) in E.T., Izaugie, M.A. And Olaitan, S.O. (eds), Implementation of National Policy on Education: Theoretical and Empirical Analysis. Ehiamatalor. Benin City: NERA Publications, University of Benin.

Dawson, N. 1997. "What primary school teachers think of drugs education in their school." Health Education Journal, 56: 364-375

Frank ham, J. 1998. "Peer education: the unauthorized version." British Educational Research Journal, 24(2): 179-193.

Gold, B.S. 1994. Health Education Teacher Resource Handbook; A practical Guide for K 12 Health Education. Newton, MA: Educational Development Centre, pp. 1-40

Idehen, C.O. 2004. Implementation of the National Health Education Curriculum in Secondary Schools in Edo State. Thesis submitted to the University of Benin, Benin City, Nigeria.

Oberteuffer, D., O. Harrelson and M. Pollock. 1985. School Health Education. $5^{\text {th }}$ Edition. New York: Harper and Row Publishers.

0wie, I. 1992. Semantic Analysis of Primary School Teachers Perception of Health Education As A School Subject. Nigerian Educational Forum, 13-1 